\title{
BIBECHANA
}

A Multidisciplinary Journal of Science, Technology and Mathematics

ISSN 2091-0762 (online)

Journal homepage: http://nepjol.info/index.php/BIBECHANA

\section{Foundations of the Fredholm Alternative Theorem, Equicontinuous Operators and Completely Continuous Operators}

\author{
G.K. Palei ${ }^{1}$, N.P. Sah ${ }^{2 *}$ \\ ${ }^{1}$ Department of Mathematics, B.N. College, Patna University, Patna, India \\ ${ }^{2}$ Department of Mathematics M.M.A.M. Campus (Tribhuvan University), Biratnagar, Nepal \\ Article history: Received 25 July, 2011; Accepted 27 Nov., 2011
}

\section{Abstract}

The Fredholm Alternative Theorem gives the notion of bounded and continuous operator which makes a family $\mathrm{F}$ of elements of $\mathrm{C}[\mathrm{a}, \mathrm{b}]$ bounded and equicontinuous. A continuous operator of finite rank is completely continuous but every continuous operator is not completely continuous operator.

Keywords: Arzela-Ascoli's theorem; completely continuous; equicontinuous and Fredholm alternative theorem

\section{Introduction}

If $X$ be a liner space over the field $\Phi$ of real or complex numbers, then the set of all linear transformations $\mathrm{T}$ from $\mathrm{X}$ into itself form a linear space $\mathrm{L}(\mathrm{X})$ on $\mathrm{X}$. The linear subspace $\mathrm{N}(\mathrm{T})=\{x \in X, T x=0\}$ is called the null space of $\mathrm{T}$ and $\mathrm{B}(\mathrm{T})=\{y \in X: T x=y, x \in X\}$ is called the image space of $\mathrm{T}$.

The Fredhlom Alternative Theorem is based on the linear algebra.

i.e. if $\operatorname{dim} X<\infty$ and $T \in L(X)$, then the following alternative holds :

Either the equation $T x=0$ has only the trivial solution $x=0$ in which case the equation $T x=y$ has a unique solution $\mathrm{x} \in \mathrm{X}$ for arbitrary $\mathrm{y} \in \mathrm{X}$.

OR

The equation $T x=0$ has nontrivial solutions in which case the equation $T x=y$ is not always solvable for each $\mathrm{y} \in \mathrm{X}$.

The above alternative theorem does not hold for infinite dimensional vector spaces. For this, consider the vector space (s) of all sequences of real or complex numbers. The map defined on (s) by $T\left(x_{1}, x_{2}, \ldots\right)=\left(0, x_{1}, x_{2} \ldots \ldots \ldots\right)$ is one to one and onto, hence $T\left(x_{1}, x_{2}, \ldots \ldots\right)=0$ has the only trivial solution $x_{1}=x_{2}=\ldots \ldots \ldots=0$ but still the equation $T x=y$ is not solvable for all $y \in(s)$ whose first component is zero.

Fredhlom has proved in his work (1900-1903) that the alternative theorem[4] is valid for a certain class of linear integral equations. 


$$
x(s)-\int_{z}^{b} k(s, t) x(t) d t=y(s)
$$

These equations are known as Fredholm integral equations. Here $K(s, t)$ is a continuous function on $[a, b] \times[a, b]$ and is called the kernel of the integral equation, $y(s)$ is continuous on $[a, b]$, and therefore $y \in C[a, b]$. As solutions only elements from $C[a, b]$ are allowed. Therefore we can write the integral equation also in the following abstract form.

$$
x-K x=(I-K) x=y,
$$

where $I$ is the identity map on $C[a, b]$ and where the linear map

$$
\mathrm{K}: \mathrm{C}[\mathrm{a}, \mathrm{b}] \rightarrow \mathrm{C}[\mathrm{a}, \mathrm{b}] \text { is defined by }
$$

$$
(k x)(s)=\int_{a}^{b} k(s, t) x(t) d t \text {. }
$$

Further, if in Fredholm Aternative Theorem we replace $\mathrm{T}$ by $\mathrm{I}-\mathrm{K}$ then in that case it reads[7]: Either the equation $(I-K) x=0$ has only the trivial solution $x=0$ in which case the equation $(I-K) x=y$ has a unique solution $\mathrm{x} \in \mathrm{C}[\mathrm{a}, \mathrm{b}]$ for arbitrary $\mathrm{y} \in \mathrm{C}[\mathrm{a}, \mathrm{b}]$.

$$
\text { OR }
$$

The equation $(I-K) x=0$ has non-trivial solution in $C[a, b]$ in which case the equation $(I-K) x=y$ is not necessarily solvable through an $\mathrm{x} \in \mathrm{C}[\mathrm{a}, \mathrm{b}]$ for arbitrary $\mathrm{y} \in \mathrm{C}[\mathrm{a}, \mathrm{b}]$.

In order to give a refinement of Fredholm Alternative Theorem we introduce the following definitions:

\section{Definition}

$\mathrm{K} \in \mathrm{L}(\mathrm{x})$ is called finite dimensional or of finite rank of $\operatorname{dim} \mathrm{B}(\mathrm{k})<\infty$.

Let $X, Y$ be vector spaces over the same field of scalars and let $\mathrm{L}(\mathrm{X}, \mathrm{Y})$ denote the vector space of all linear mappings of $X$ into $Y$. let $T \in L(X, Y)$. Then $\alpha(T)=\operatorname{dimN}(T)$ is called the kernel index of $T([1][.2])$.

$\beta(T)=\operatorname{Co}-\operatorname{dim} B(T)=\operatorname{dim} Y / B(T)$ is called the deficiency index of $T$.

The following theorem is a refinement of fredholm alternative theorem:

Theorem: If $\mathrm{K}$ is a finite dimensional map of $\mathrm{X}$ into itself then $\alpha(\mathrm{I}-\mathrm{K})=\beta(\mathrm{I}-\mathrm{K})<\infty$.

Proof :

(a) we first show that $\alpha(I-K) \leq \operatorname{dimB}(K)$, in fact if $x \in N(I-K)$ then $x=K x$, hence $N(I-K) \subseteq B(K)$ and $\alpha$ $(\mathrm{I}-\mathrm{K}) \leq \operatorname{dimB}(\mathrm{K})$.

(b) We put $\mathrm{Y}=\mathrm{B}(\mathrm{K})$. Since $\mathrm{B}\left(\mathrm{K}^{2}\right) \subseteq \mathrm{B}(\mathrm{K}), \mathrm{K}$ and hence also $\mathrm{I}-\mathrm{K}$ map $\mathrm{Y}$ into itself. We denote the restrictions of $\mathrm{I}, \mathrm{K}$ to $\mathrm{Y}$ by $\tilde{I}, \widetilde{K}$. By (a) we have $(\tilde{I}-\widetilde{K})=N(I-K)$, if $\mathrm{Z}$ is an algebric components space of $B(\tilde{I}-\widetilde{K})$ in $\mathrm{Y}$ then $\mathrm{Z}$ has finite dimension since $\operatorname{dim} \mathrm{Y}<\infty$. Now, Since $\tilde{I}-\widetilde{K}$ is a map of a finite dimensional space into itself, we have $\alpha(\tilde{I}-\widetilde{K})=\beta(\tilde{I}-\widetilde{K})$ and hence $\alpha(I-K)=\operatorname{dim} Z$.

(c) we show that $\operatorname{din} Z=\mathrm{B}(\mathrm{I}-\mathrm{K})$, from which the result follows due to (b), For this purpose we prove that $\mathrm{X}=\mathrm{Z} \oplus \mathrm{B}(\mathrm{I}-\mathrm{K})$ or equivalent that $\mathrm{X}=\mathrm{Z}+\mathrm{B}(\mathrm{I}-\mathrm{K})$ and $\{0\}=\mathrm{Z} \cap \mathrm{B}(\mathrm{I}-\mathrm{K})$. If $\mathrm{y}=(\mathrm{I}-\mathrm{K}) \mathrm{x}, \mathrm{x} \in \mathrm{X}$, then for suitable $g \in \mathrm{G}, \mathrm{z} \in \mathrm{Y}$ we have

$$
\mathrm{x}=\mathrm{y}+\mathrm{Kx}=\mathrm{y}+(\mathrm{g}+(\mathrm{I}-\mathrm{K}) \mathrm{z})=\mathrm{g}+(\mathrm{I}-\mathrm{K})(\mathrm{x}+\mathrm{z}) \text {, therefore } \mathrm{X}=\mathrm{G}+\mathrm{B}(\mathrm{I}-\mathrm{K}) . \text { If } \mathrm{u} \in \mathrm{Z} \cap \mathrm{B}(\mathrm{I}-\mathrm{K})
$$

then $\mathrm{u}=(\mathrm{I}-\mathrm{K}) \mathrm{v} \in \mathrm{Z}$. Then $\mathrm{v}=\mathrm{u}+\mathrm{Kv} \in \mathrm{Y}$, therefore $\mathrm{u}=(\mathrm{I}-\mathrm{K}) \mathrm{v} \in \mathrm{B}(\mathrm{I}-\mathrm{K}) \cap \mathrm{Z}=\{0\}$. This complete the proof.

\section{Illustration :}

The vector space $C[a, b]$ becomes a Banach space if we define $\|x\|=\sup |x(t)|$ for all $t \in[a, b]$. As $K(s, t)$ is continuous on the closed rectangle $[\mathrm{a}, \mathrm{b}] \mathrm{x}[\mathrm{a}, \mathrm{b}]$ 
We have $|\mathrm{K}(\mathrm{s}, \mathrm{t})| \leq \mu$ for all $\mathrm{s}, \mathrm{t} \in[\mathrm{a}, \mathrm{b}]$, from which we get

$$
\begin{aligned}
|(\mathrm{K} x)(\mathrm{s})| & \leq \int_{a}^{b}|K(s, t)||x(t)| d t \\
& \leq \mu .\|\mathrm{x}\| .(\mathrm{b}-\mathrm{a})
\end{aligned}
$$

Therefore $\|\mathrm{Kx}\| \leq(\mathrm{b}-\mathrm{a}) \mu$. $\|\mathrm{x}\|$. Hence $\mathrm{K}$ is a bounded operator and therefore, also a continuous operator in other words, $\mathrm{K}$ maps every bounded subset of $\mathrm{C}[\mathrm{a}, \mathrm{b}]$ into a bounded subset of $\mathrm{C}[\mathrm{a}, \mathrm{b}]$.

\section{Definition}

A family $\mathrm{F}$ of elements of $\mathrm{C}[\mathrm{a}, \mathrm{b}]$ is said to be equicontinuous, if to each $\in>0$, there exists a $\delta=\delta(\epsilon)>0$, s.t. for all $\mathrm{t}_{1}, \mathrm{t}_{2} \in \mathrm{X},\left|\mathrm{t}_{1}-\mathrm{t}_{2}\right|<\delta$ implies $\left|\mathrm{y}\left(\mathrm{t}_{1}\right)-\mathrm{y}\left(\mathrm{t}_{2}\right)\right|<\in$ for all $\mathrm{y} \in \mathrm{F}$.

Lemma : If $M$ is a bounded set in $C[a, b]$ then $F=\{K x: x \in M\}$ is a bounded and equicontinuous family. Proof :

We have seen above that $F$ is bounded. Now, it remains to show that $F$ is equi continuous. As $\mathrm{K}(\mathrm{s}, \mathrm{t})$ is uniformly continuous on $[\mathrm{a}, \mathrm{b}] \mathrm{x}[\mathrm{a}, \mathrm{b}]$ given $\in>0$, there exists $\mathrm{a} \delta>0$ s.t.

$$
\begin{aligned}
& \left|\mathrm{K}\left(\mathrm{s}_{1}, \mathrm{t}\right)-\mathrm{K}\left(\mathrm{s}_{2}, \mathrm{t}\right)\right|<\frac{\in}{(b-a) \gamma} \text { for all } \mathrm{t} \in[\mathrm{a}, \mathrm{b}] \text { provided }\left|\mathrm{s}_{1}-\mathrm{s}_{2}\right|<\delta . \\
& \text { Hence } \quad \begin{aligned}
\left|\mathrm{y}\left(\mathrm{s}_{1}\right)-\mathrm{y}\left(\mathrm{s}_{2}\right)\right| & =\left|\int_{a}^{b}\left[K\left(s_{1}, t\right)-K\left(s_{2}, t\right)\right] \cdot x(t) d t\right| \\
& \leq \int_{a}^{b}\left|K\left(s_{1}, t\right)-\left(s_{2}, t\right)\right||x(t)| d t \\
& <\frac{\in(b-a) \gamma}{(b-a) \gamma} \\
& =\in, \text { provided }\left|\mathrm{s}_{1}-\mathrm{s}_{2}\right|<\delta
\end{aligned}
\end{aligned}
$$

Hence $\mathrm{F}$ is equicontinuous.

For further we need the Arzela-Ascoli's Theorem.

\section{Arzela - Ascoli's Theorem}

If $\mathrm{F}$ is a bounded and equicontinuous family in $\mathrm{C}[\mathrm{a}, \mathrm{b}]$ then every sequence of elements of $\mathrm{F}$ contains a convergent subsequence[3].

From Arzela - Ascoli's theorem it follows that the image sequence $\mathrm{Kx}_{1}, \mathrm{Kx}_{2}, \mathrm{Kx}_{3}, \ldots$ of a bounded sequence is $\mathrm{C}[\mathrm{a}, \mathrm{b}]$ contains a convergent sebsequence. Riesz has constructed the theory of Fredholm integral equations on this property of $\mathrm{K}[6]$.

\section{Definition}

If $\mathrm{E}$ and $\mathrm{F}$ are normed linear spaces then a map $\mathrm{K} \in \mathrm{L}(\mathrm{E}, \mathrm{F})$ is called completely continuous if for every bounded sequence $\left\{\mathrm{x}_{\mathrm{n}}\right\}$ in $\mathrm{E}$, the image sequence $\left\{\mathrm{Kx}_{\mathrm{n}}\right\}$ in $\mathrm{F}$ has a convergent sebsequence.

Lemma : A completely continuous linear operator $\mathrm{K}$ is continuous. Suppose if $\mathrm{K}$ is not continuous, $\mathrm{K}$ is not bounded, Sup $\left\|\mathrm{Kx}_{\mathrm{n}}\right\|=\infty$, hence there exists a sequence $\left\{\mathrm{x}_{\mathrm{n}}\right\}$ with $\left\|\mathrm{x}_{\mathrm{n}}\right\| \leq 1$ and $\left\|\mathrm{Kx}_{\mathrm{n}}\right\| \rightarrow \infty$ which contradicts that $\mathrm{K}$ is completely continuous.

But every continuous operator is not completely continuous. For example, the identity map I on an infinite dimensional normed linear space is continuous but not completely continuous [2,5]. 
Theorem: A continuous operator $\mathrm{K}$ of finite rank is completely continuous.

\section{Proof :}

If $\left\{x_{n}\right\}$ is a bounded sequence in $E$, then the image sequence $\left\{\mathrm{Kx}_{n}\right\}$ in $F$ is bounded. Now, Since $B(K)$ i.e. the image space of $\mathrm{K}$ is finite dimensional, hence $\mathrm{B}(\mathrm{K})$ is complete. Hence applying Bolzano. Weierstrass theorem it follows that there exists a convergent sebsequence $\left\{\mathrm{Kx}_{\mathrm{n}}\right\}$.

\section{Reference}

[1] Bruce Biackadar, Operator Algebras, Encyelopedia of Mathematical Sciences, Springer Verlag, 2005.

[2] John B Conway, A course on Funtional Analysis Springer - Verlag, 1985.

[3] S. Goldberg, Unbounded linear operators, Mc. Graw Hill, New Yorks, 1966.

[4] K hvedelidge : Fredholm Theorem, Encyclopedia of Maths, Springer - Verlag, 2001

[5] G. Kothe, Top, Vector space, I and II Springer Verlag, 1969.

[6] Alena Pietro A Characterization of Riesz operators : In the Journal of "Mathematiche Zeitschrift, springer-Berlin, 2005.

[7] A.G. Ramm, A simple proof of the Fredholm Alternative and Characterization of the Fredholm operators, American Mathematical Monthly Journal P.815; 2001. 